\title{
Corrigendum
}

\section{Corrigendum to "Adaptive Digital Watermarking Scheme Based on Support Vector Machines and Optimized Genetic Algorithm"}

\author{
Xiaoyi Zhou $\mathbb{D}^{1},{ }^{1}$ Chunjie Cao $\mathbb{D D}^{1},{ }^{1}$ Jixin $M a \mathbb{D}^{2},{ }^{2}$ and Longjuan Wang $\mathbb{D}^{1}$ \\ ${ }^{1}$ School of Computer Science and Technology, Hainan University, Haikou, China \\ ${ }^{2}$ School of Computing and Mathematical Sciences, University of Greenwich, London, UK \\ Correspondence should be addressed to Xiaoyi Zhou; xy.zhou.xy@gmail.com and Longjuan Wang; 40552382@qq.com \\ Received 24 April 2021; Accepted 24 April 2021; Published 12 May 2021 \\ Copyright (C) 2021 Xiaoyi Zhou et al. This is an open access article distributed under the Creative Commons Attribution License, \\ which permits unrestricted use, distribution, and reproduction in any medium, provided the original work is properly cited.
}

The authors wish to clarify that the article titled "Adaptive Digital Watermarking Scheme Based on Support Vector Machines and Optimized Genetic Algorithm" [1] is a translated and extended version of an article originally published in Modern Electronics Technique, 2016 [2].

\section{References}

[1] X. Zhou, C. Cao, J. Ma, and L. Wang, "Adaptive Digital Watermarking Scheme Based on Support Vector Machines and Optimized Genetic Algorithm," Mathematical Problems in Engineering, vol. 2018, Article ID 2685739, 9 pages, 2018.

[2] X. Li, X. Zhou, and C. Cao, "Image DCT transform domain watermarking technology based on improved genetic algorithm and SVM," Modern Electronic Technology, vol. 20, 2016. 